\title{
LITERASI INFORMASI KECANTIKAN DI KALANGAN PENGGUNA FEMALE DAILY NETWORK
}

\author{
Sarah Derma Ekaputri ${ }^{1 *}$, Cut Meutia Karolina ${ }^{2}$, Nisa N. Abdullah ${ }^{3}$ \\ ${ }^{1,2,3}$ Program Studi Magister Ilmu Komunikasi Universitas Padjadjaran \\ *Korespondensi: sarah18014@mail.unpad.ac.id
}

Diajukan: 16-06-2019; Direview: 07-08-2019; Diterima: 02-02-2020; Direvisi: 08-03-2020

\begin{abstract}
The presence of Female Daily Network is giving convenience in accessing and sharing various information about the beauty. This research aims to know the information literacy among the users of Female Daily Network. This research uses descriptive quantitatives method. This research shows that information literation about beauty amongst users can be categorized as high with the average score of $75,95 \%$. It indicates that this platform can fulfill the needs of beauty information by users. The majority of users consist of productive female adolescents who really need beauty information that supports their needs of daily life appearance, as well as to overcome various beauty problems.
\end{abstract}

\begin{abstract}
ABSTRAK
Hadirnya Female Daily Network memberikan kemudahan dalam mengakses dan berbagi informasi tentang kecantikan. Penelitian ini bertujuan untuk mengetahui literasi informasi kecantikan di kalangan pangguna Female Daily Network. Metode penelitian yang digunakan adalah kuantitatif deskriptif. Hasil penelitian menunjukkan bahwa literasi informasi kecantikan di kalangan pengguna termasuk kedalam kategori tinggi dengan nilai rata-rata sebesar $75,95 \%$. Artinya bahwa platform ini dapat memenuhi kebutuhan informasi kecantikan pengguna. Sebagian besar pengguna terdiri dari remaja perempuan produktif ini sangat membutuhkan informasi kecantikan untuk mendukung penampilannys dalam kehidupan sehari-hari, serta untuk mengatasi berbagai permasalahan kecantikan.
\end{abstract}

Keywords: Information literacy; Digital literacy; User generated content; Female Daily Network

\section{PENDAHULUAN}

Industri kecantikan dalam beberapa tahun terakhir terus menunjukkan perkembangan dan menjadi salah satu industri yang strategis dan potensial. Berbagai tren kecantikan mendorong para produsen produk kecantikan, baik produk perawatan kecantikan (skincare) maupun produk rias wajah (makeup), terus berinovasi dan menghasilkan produk yang sesuai dengan kebutuhan pasar. Tren ini umumnya berasal dari industri kecantikan Korea Selatan yang dikenal dengan istilah K-Beauty. Badan Pusat Statistik (BPS) mencatat impor produk kecantikan Korea Selatan mencapai \$ 5,9 juta pada 2016 (Putri, 2017). Volume impor produk kecantikan luar negeri meningkat, bahkan dapat menguasai pangsa pasar sebesar $60 \%$ dari total pasar domestik (Bisnis Indonesia n.d.).

Konsumsi produk kecantikan memiliki beberapa resiko, seperti kandungan produk yang kurang baik atau tidak cocok dengan kulit, orisinalitas produk, dan aspek halal. Berbagai produk kecantikan impor yang belum memperoleh izin dari BPOM dan sertifikasi halal dari MUI. Idealnya dalam menggunakan produk kecantikan harus menimbang beberapa syarat, antara lain (1) produk telah memiliki izin dari BPOM, artinya produk dinilai aman dari kandungan yang berbahaya; (2) bahan aktif yang terkandung dalam produk sesuai dengan kebutuhan kulit; (3) menggunakan produk dalam dosis yang sesuai dengan instruksi pemakaian; (4) melakukan uji alergi sebelum menggunakan produk (Alodokter n.d.) 
Kecantikan merupakan topik yang kompleks, bukan sekedar tentang menggunakan produk untuk memperindah diri, tapi juga menyangkut aspek sains, medis, dan aspek sosioekonomi. Mengkonsumsi produk kecantikan perlu dibarengi dengan pertimbangan tertentu agar penggunaannya dapat menjadi efektif dan meminimalisasi dampak negatif dari kesalahan penggunaan produk. Menurut Sukritiani (2014) pengaruh yang ditimbulkan oleh produk kecantikan dapat digolongkan menjadi dua, yaitu (1) pengaruh positif, dimana penggunaannya dapat menjadikan kulit bersih, sehat dan segar serta menjadi lebih muda, dengan pemilihan produk yang sesuai dengan jenis kulit serta teknik/cara pemakaian yang tepat dan teratur; (2) pengaruh negatif yang akan menimbulkan masalah pada kulit, seperti gatal, kemerahan, bengkak ataupun timbul noda hitam, yang tidak diharapkan.

Perkembangan teknologi informasi dan komunikasi yang semakin canggih membuat khalayak semakin dipermudah untuk mencari tahu informasi tentang produk dan informasi terkait pemenuhan kebutuhan kecantikan. Kemudahan dalam mencari informasi dan ledakan informasi yang tersedia tidak serta-merta berasal dari sumber yang memiliki kredibilitas dan menjamin khalayak terpapar dengan informasi yang akurat. Khalayak harus kritis dalam menganalisis informasi yang diperoleh agar terhindar dari dampak negatif akibat kesalahan dalam konsumsi produk kecantikan.

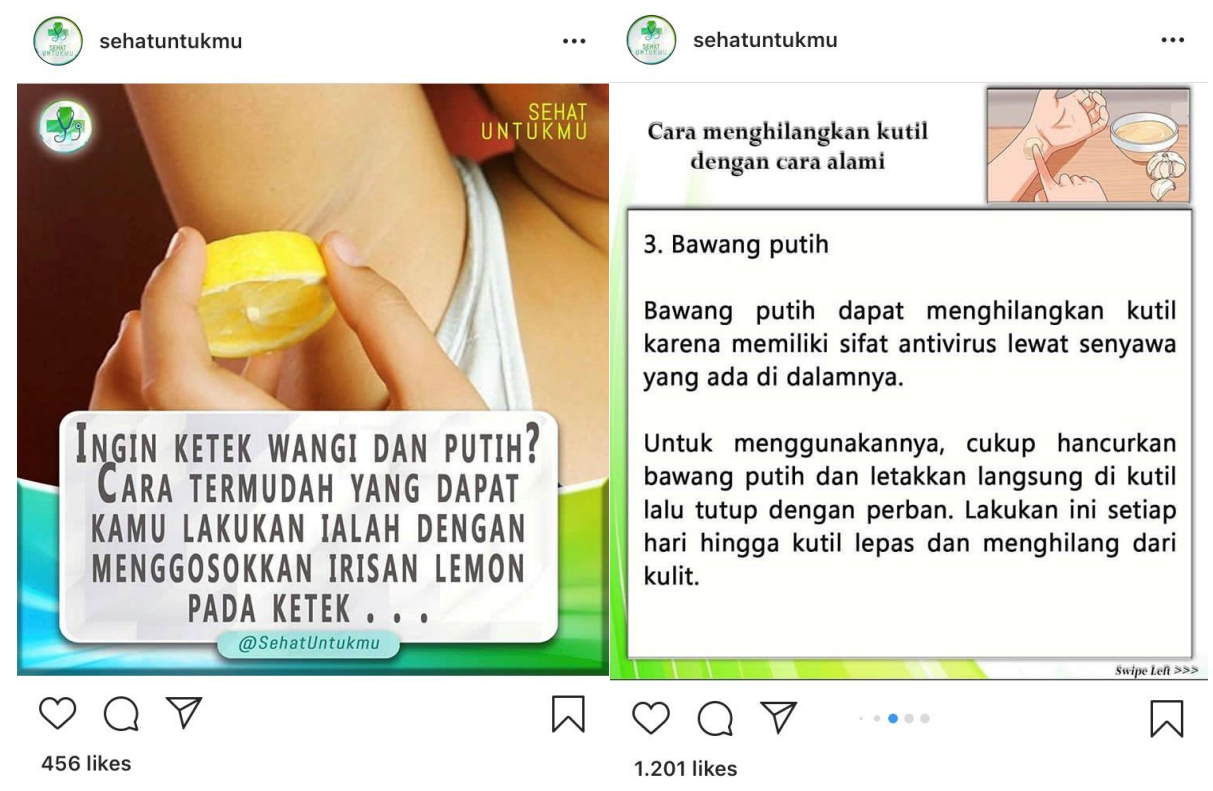

Gambar 1: Hoax Kecantikan di Instagram

(Sumber: Instagram@sehatuntukmu, 2019)

Selain melalui media sosial beauty influencer, informasi kecantikan di Indonesia dapat diperoleh melalui Platform User-Generated Content (UGC), seperti Female Daily Network. Female Daily Network merupakan platform kecantikan yang berbasis di laman www.femaledaily.com dan aplikasi mobile. Female Daily Network memiliki fitur yang memungkinkan terjadinya interaktif dikalangan penggunanya. Seperti mendapatkan informasi seputar kecantikan lewat membaca blog atau editorial dan menyaksikan video yang diunggah melalui akun Youtube Female Daily Network, berinteraksi dengan sesama pengguna atau berdiskusi tentang topik-topik kecantikan tertentu melalui fitur Forum, serta menuliskan 
review terkait produk kecantikan tertentu dan menambahkan produk kecantikan ke fitur Database.

Menurut riset pasar Zap Beauty Index Agustus 2018 (Markplus.inc, 2018), sebelum membeli produk kecantikan, $73,2 \%$ perempuan terlebih dahulu mencari informasi produk secara online yang tersedia dalam bentuk review. Adapun media yang digunakan dalam mencari informasi tersebut adalah Instagram (55\%), Youtube (41,6\%), dan sumber langsung dari merek yang bersangkutan melalui laman web atau beauty advisor $(25,7 \%)$. Bahkan perempuan Indonesia lebih mempercayai informasi yang diberikan oleh beauty influencer $(40,9 \%)$ dibandingkan teman mereka $(38,1 \%)$. Hal ini membuktikan bahwa, terlepas dari tidak terjaminnya akurasi informasi di dalamnya, internet justru memegang peranan penting dalam pemenuhan informasi kecantikan di kalangan perempuan.

Konsumsi produk kecantikan harus diimbangi dengan keterampilan dalam mencari, menemukan, dan menganalisis informasi tentang kesehatan dan kondisi kulit komposisi kandungan produk yang aman dan dibutuhkan; menemukan sumber informasi yang memiliki kredibilitas; menganalisis berbagai informasi; dan menggunakan informasi untuk diaplikasikan pada diri sendiri atau membuat keputusan konsumsi produk kecantikan. Keterampilan literasi informasi dibutuhkan dalam konsumsi produk kecantikan agar tercapainya efektivitas dan efisiensi dari produk kecantikan yang digunakan.

Keterampilan literasi yang dibutuhkan saat ini adalah literasi digital. Menurut Jeffrey, et al. (2017) literasi digital erat kaitannya dengan self-efficacy (potensi diri) yang dimiliki seseorang dalam menggunakan teknologi. Seseorang yang memiliki self-efficacy dalam penggunaan teknologi, tidak otomatis memiliki tingkat literasi digital yang tinggi. Rasa percaya diri yang tinggi dalam kecakapan digital, sering kali tidak diikuti dengan kesadaran pentingnya kemampuan mengevaluasi kualitas informasi yang diperoleh. Mengingat sebagian besar perempuan mencari informasi kecantikan secara online, keterampilan literasi digital juga dapat dikatakan penting dalam hal kecantikan. Penelitian tentang literasi yang berkaitan dengan digital dan media baru di kalangan remaja dan perempuan menjadi cukup populer dalam penelitian sosial, khususnya pada penelitian komunikasi (Luthfia, 2018; Amanda, Prijana, \& Yanto, 2017; Ilahi, 2019). Penelitian tersebut menunjukkan bahwa kurangnya literasi media dan kecenderungan untuk memprioritaskan aspek emosional dari sebuah cerita membuat perempuan rentan mempercayai dan menyebarkan hoax.

Terkait hal tersebut, peneliti menjelaskan literasi digital pada pengguna platform Female Daily Network, khususnya informasi kecantikan. Female Daily Network memberikan kemudahan dalam mencari dan memperoleh informasi kecantikan yang berguna dalam pengambilan keputusan dalam konsumsi produk kecantikan. Female Daily Network menjadi objek penelitian karena platform ini termasuk salah satu platform kecantikan yang paling populer di Indonesia. Female Daily Network setiap harinya memiliki 450 pengguna baru yang mendaftar sebagai anggota; 7,5 juta kunjungan laman web per-bulan, lebih dari 355.000 pengikut di berbagai channel media social; 2 juta unique users per-bulannya. Penelitian ini bertujuan untuk mengetahui tingkat literasi informasi kecantikan dikalangan pengguna Female Daily Network.

\section{TINJAUAN PUSTAKA}

\subsection{Literasi Informasi}

Menurut Anunobi \& Udem (2014), informasi dianggap sebagai pengetahuan ketika melakukan peran memberikan pengetahuan kepada orang lain. Melalui informasi maka 
tercipta pengurangan ketidakpastian terhadap pengetahuan informasi yang sedang dicari. Informasi dibagi menjadi tiga kelompok, yaitu: (a) apapun yang dianggap berpotensi menandakan sesuatu (misalnya buku cetak); (b) proses menginformasikan; (c) apa yang dipelajari dari beberapa bukti atau komunikasi. American Library Association mendefinisikan literasi informasi sebagai seperangkat kemampuan yang memberdayakan individu untuk mengenali kapan informasi dibutuhkan dan bagaimana menemukan, mengevaluasi, serta menggunakannya secara efektif (Hisle, David, \& Webb, 2017).

UNESCO mendefinisikan literasi informasi sebagai sebuah kemampuan seseorang untuk: (1) menyadari kebutuhan informasi; (2) menemukan dan mengevaluasi kualitas informasi yang diperoleh; (3) menyimpan dan menemukan kembali informasi; (4) membuat dan menggunakan informasi secara etis dan efektif; dan (5) Mengkomunikasikan pengetahuan (Silvana, Fitriawati, \& Saepudin, 2017). Stock \& Stock (2013) mengatakan bahwa literasi informasi tentang bagaimana seseorang melakukan penggunaan pengetahuan sains informasi. Literasi informasi berkaitan dengan bagaimana seseorang mampu mengelola informasi yang didapatkan mulai dari kesadaran akan kebutuhan informasi tersebut, hingga mengkomunikasikan informasi yang diperoleh.

Seseorang yang memiliki kemampuan literasi informasi, hendaknya mampu menentukan sejauh mana informasi yang dibutuhkan; mengakses informasi yang diperlukan secara efektif dan efesien; mengevaluasi informasi dan keputusannya secara kritis; memasukkan informasi yang dipilih ke dalam basis pengetahuan mereka; menggunakan informasi secara efektif untuk mencapai tujuan tertentu; memahami masalah ekonomi, hukum, dan sosial seputar penggunaan informasi; mengakses serta menggunakan informasi secara etik dan legal (Sales \& Pinto, 2016). Istilah baru literasi informasi yaitu information fluency - gabungan dari information literacy dan IT fluency (Lombard, 2016). Istilah tersebut kemudian dikenal sebagai digital information fluency, yang berarti kemampuan untuk menemukan, mengevaluasi, dan menggunakan informasi digital secara efektif, efisien dan etis.

\subsection{Literasi Digital}

Dunia informasi digital sudah sangat berkembang dengan pesat sehingga sumber informasinya sudah beragam (UNESCO, 2011). Literasi digital berkaitan dengan bagaimana seseorang mampu menetapkan, mengakses, mengevaluasi, dan mengelola informasi melalui perangkat teknologi informasi yang dapat menjadi bahan pengambilan keputusan dengan tepat (Van-Laar, et al., 2017). Menurut Chetty, et al., 2018), literasi digital memberi seseorang kemampuan inti untuk mencapai hasil yang bernilai dalam kehidupan. Literasi digital mendukung transformasi ekonomi melalui promosi peluang kerja. Anunobi \& Udem (2014) menjelaskan ada beberapa komponen penting literasi digital, yaitu: (1) akses informasi, yaitu pengidentifikasian sumber informasi dengan teknik tertentu untuk mengumpulkan dan mengambil informasi; (2) integrasi, melibatkan interpretasi dan representasi informasi menggunakan teknologi, dengan cara mensintesis, merangkum, membandingkan, dan membedakan informasi dari berbagai sumber; (3) penciptaan, suatu tindakan yang menghasilkan informasi baru secara digital dengan mengadaptasi, menerapkan, merancang, menciptakan, atau menulis informasi; (4) komunikasi, mendukung literasi lain melalui penggunaan media yang paling tepat untuk menyajikan informasi yang baik dalam berbagai konteks sosial budaya.

Menurut Kay \& Ahmadpour (2015) ada lima sub-kategori literasi digital, yaitu literasi foto visual, literasi reproduksi, literasi informasi, literasi percabangan, dan literasi sosial 
emosional. Literasi foto visual mengacu pada kemampuan untuk membaca representasi visual dari lingkungan digital, menggabungkan teks, suara, gambar, dan simbol. Literasi reproduksi menandakan kemampuan untuk membuat dan mereproduksi pengetahuan yang ada dari lingkungan yang kaya informasi. Literasi informasi berfokus pada kemampuan untuk mengakses, menemukan, dan mengevaluasi informasi yang berasal dari beberapa sumber. Keaksaraan bercabang memandang hypermedia dan kemampuan yang kita butuhkan untuk bernavigasi di dunia hypermedia yang interaktif dan non-linear. Akhirnya, melek sosial dan emosional mengacu pada kemampuan seseorang untuk berperilaku tepat di dunia maya.

Menurut Chetty, et al. (2018), literasi digital menawarkan pembuat kebijakan untuk memantau difusi keterampilan digital. Melalui pengukuran literasi digital memungkinkan pembuat kebijakan untuk mengukur tingkat keterampilan sebuah negara terhadap norma internasional, jika standar yang sama diterima secara internasional. Tanpa indikator, pengukuran yang konsisten dan komparatif untuk mengidentifikasi sektor-sektor populasi yang buta huruf secara digital, akan membuat kebijakan tidak berdaya, dan tidak akan mampu mengimplementasikan tujuan transformasi digital.

\subsection{Model The Big Six}

Eisenberg dalam Kay \& Ahmadpour (2015) menekankan tiga komponen penting dalam keberhasilan pembelajaran dan pengajaran literasi informasi, yaitu proses informasi, teknologi, dan kebutuhan nyata. Menurutnya proses informasi memberi siswa sebuah struktur, sehingga mereka mengetahui cara pemecahan masalah. Ketiga komponen ini merupakan perkembangan model The Big Six yang dicetuskan pada tahun 1990. Model The Big Six merupakan sebuah pendekatan dalam proses literasi informasi yang dikembangkan oleh Mike Eisenberg dan Bob Berkowitz. Model ini mengintegrasikan keterampilan pencarian dan penggunaan informasi dengan teknologi dalam sebuah proses sistematis untuk menemukan, menggunakan, menerapkan, dan mengevaluasi informasi untuk kebutuhan tertentu (Biradar, 2017).

Model ini terus digunakan dalam penelitian komunikasi, khususnya pada kegiatan literasi informasi. Eisenberg mengatakan bahwa berbagai keterampilan komputer dan teknologi informasi adalah bagian integral dari keterampilan Big6 (Walter, 2007). Menurut Bartow \& Marion (2019), model proses informasi dengan The Big Six ada enam tahapan, sebagaimana dijelaskan pada Tabel 1.

Tabel 1. Tahapan dalam Model The Big Six

\begin{tabular}{|c|c|c|}
\hline No. & Tahapan (Level) & Sub-Tahapan (Sub-Level) \\
\hline 1 & Task Definition & $\begin{array}{l}\text { - Define the information problem } \\
\text { - Identify information needed }\end{array}$ \\
\hline 2 & $\begin{array}{l}\text { Information } \quad \text { Seeking } \\
\text { Strategies }\end{array}$ & $\begin{array}{l}\text { - } \quad \text { Determine all possible sources } \\
\text { - } \quad \text { Select the best sources }\end{array}$ \\
\hline 3 & Location and Access & $\begin{array}{l}\text { - Locate sources (intellectually and } \\
\text { physically) } \\
\text { - } \quad \text { Find information within sources }\end{array}$ \\
\hline 4 & Use of Information & $\begin{array}{ll}- & \text { Engage (read, hear, view, touch) } \\
-\quad & \text { Extract relevant information }\end{array}$ \\
\hline
\end{tabular}




\begin{tabular}{|c|l|ll|}
5 & Synthesis & $\begin{array}{l}\text { Organize from multiple sources } \\
\text { - Present the information }\end{array}$ \\
\hline 6 & Evaluation & - Judge the product (effectiveness) \\
\hline
\end{tabular}

Sumber: Bartow and Marion (2019); Kay \& Ahmadpour (2015)

- Level task definition. Pada level ini, terjadi penentuan tugas yang terdiri dari dua sublevel, yakni menentukan permasalahan informasi dan mengidentifikasi kebutuhan informasi. Pengelolaan informasi pada individu diawali dari pendefinisian tugasnya. Pendefinisian dimulai dari mendefinisikan permasalahan informasi yang dihadapi dan mengidentifikasi kebutuhan informasi.

- Level information seeking strategies. Pada level ini, seseorang akan mengelola informasi melalui penyusunan strategi untuk memperoleh informasi. Level ini dilakukan melalui dua sub-level, yakni melalui penentuan sumber-sumber informasi yang memungkinkan dan pemilihan sumber yang terbaik.

- Level location and access. Pada level ini, seseorang telah mengetahui dimana ia mendapatkan sumber informasi tersebut, serta menemukan informasi yang dicari dalam sumber tersebut. Individu akan mengetahui sumber yang mana yang dapat didatangi untuk memenuhi kebutuhan informasi tertentu.

- Level use of information. Pada level ini, individu akan menggunakan informasi dengan cara membaca, melihat, mendengar, atau menyentuhnya. Individu akan mengekstraksi informasi yang didapatkan melalui penggunaan yang dilakukan.

- Level synthesis. Melalui level ini individu akan mengatur informasi yang diperoleh dari berbagai sumber dan menampilkan informasi tersebut.

- Level evaluation. Tahap ini informasi dan penggunaannya akan dinilai dari sisi efektivitas dan efisiensinya.

\subsection{User Generated Content}

Internet memasuki domain publik Indonesia pada tahun 1995 dengan kedatangan Internet Service Provider (ISP) komersial swasta, diikuti dengan booming ISP pada akhir tahun 1997, dan mempengaruhi aspek sosial budaya, yakni muncul warung internet dan media sosial yang dapat diakses melalui perangkat mobile (Lim, 2018). Internet mengalami perkembangan dari Web 1.0 menuju Web 2.0, yang lebih interaktif dan kolaboratif penggunanya (Newman, et al., 2016). Web 2.0 juga memungkinkan penggunanya untuk menciptakan konten baru (Pieri \& Diamantini, 2014). Platform berbasis User Generated Content (UGC) merupakan bentuk produk Web 2.0 yang sering digunakan untuk media sosial.

UGC berbentuk ulasan produk online, menargetkan pengguna dengan pengguna lainnya dengan memberikan informasi UGC yang di-posting di website berbeda oleh satu pengguna berisi redundansi informasi yang besar ( $\mathrm{Li}$, et al., 2018). Pengguna berkontribusi dalam menciptakan konten sendiri - disebut sebagai 'creative effort'. Creative effort berisi komentar dalam konten lain, seperti blog atau artikel online; meneliti dan menyiapkan informasi; mengunggah teks, gambar, dan audio (Naab \& Sehl, 2017). Salah satu platform UGC yang bertema kecantikan adalah Female Daily Network (www.femaledaily.com). Platform ini merupakan online beauty-hub Indonesia yang memungkinkan penggunanya untuk aktif 
menciptakan creative effort dalam topic kecantikan. Melalui website dan smartphone, pengguna dapat membaca dan menyaksikan informasi seputar kecantikan, me-review berbagai produk kecantikan, berdiskusi dengan sesama pengguna terkait topik kecantikan, dan menjalin pertemanan melalui media sosial lainnya.

\section{METODE}

Menurut Sugiyono (2013), metode adalah cara ilmiah untuk mendapatkan data dengan tujuan dan kegunaan tertentu. Dengan cara ilmiah, kegiatan penelitian berdasarkan pada ciriciri keilmuan, yaitu rasional, empiris, dan sistematis. Penelitian ini menggunakan data kuantitatif. Data kuantitatif diuji dengan model The Big Six. Hasil penelitian persentase (\%) level literasi informasi pengguna Female Daily Network berdasarkan model The Big Six dari Mike Eisenberg dan Bob Berkowitz, yaitu task definition, information seeking strategies, location and access, use of information, synthesis, dan evaluation. Sebelum menganalisis enam komponen tersebut, peneliti melakukan survei karakteristik responden. Sampel penelitian dihitung dengan presisi $10 \%$, dengan tingkat kepercayaan $90 \%$. Berdasarkan hal tersebut, sampel penelitian ditetapkan sebanyak 82 responden, berdasarkan rumus berikut ini.

$$
\begin{gathered}
\mathrm{n}=\frac{N}{N d^{2}+1} \\
\mathrm{n}=\frac{450}{450(0,1)^{2}+1} \\
\mathrm{n}=81,8=82
\end{gathered}
$$

Hasil penghitungan dan analisis data menjadi bahan pembahasan dan kesimpulan penelitian.

\section{HASIL DAN PEMBAHASAN}

Dari 82 responden pengguna Female Daily Network, diketahui sebanyak 81 orang (99\%) perempuan. Sebagian besar responden berusia dikisaran $21-25$ tahun (58 orang atau $71 \%$ ). Jumlah pengeluaran per-bulan antara $1.000 .000-2.500 .000$ untuk 38 responden (46\%). Hal tersebut mengindikasikan bahwa sebagian besar responden berasal dari remaja perempuan pada usia produktif yang berasal dari Socioeconomic Status B (SES B).

Tujuan responden menggunakan Platform Female Daily Network untuk mencari informasi kecantikan, membaca artikel atau menonton video tentang kecantikan, membaca review produk kecantikan (skincare/ makeup/tools), berdiskusi dan bertanya tentang masalah kecantikan di fitur forum dan lain-lain. Dari bermacam-macam tujuan diatas, responden paling banyak mengakses Platform Female Daily Network untuk membaca review produk kecantikan (skincare/ makeup/tools), yakni sebanyak 55 responden (67\%). Hal ini menunjukkan bahwa Platform Female Daily Network digunakan sebagai acuan responden dalam mencari informasi lebih lanjut seputar produk kecantikan yang akan dibeli atau digunakan.

Terkait media yang digunakan, mayoritas responden menggunakan smartphone dalam setiap mengakses informasi (75 responden atau 91\%) dengan frekuensi mengakses sebanyak 1 - 5 kali dalam sebulan (65\%). Smartphone dianggap menjadi perangkat yang paling mudah digunakan. Hal ini didukung oleh fakta cukup tingginya penetrasi penggunaan smartphone di Indonesia. Dari total $67 \%$ pemilik perangkat seluler di 11 kota di Indonesia yang di survey 
Nielsen (2017), diketahui bahwa pemilik smartphone telah mencapai 44\%, dan jumlahnya terus meningkat setiap tahun. Riset APJII (2017) juga menunjukkan bahwa penetrasi internet paling dominan adalah di kawasan urban $(72,41 \%)$.

Dilihat dari hasil analisis data statistik terlihat beberapa tanggapan responden terhadap setiap pertanyaan yang diajukan. Pertanyaan tersebut bersumber dari hasil turunan operasional - variabel enam komponen model The Big Six. Tabel 2 menunjukkan hasil analisis data dari enam komponen literasi informasi The Big Six.

Tabel 2. Nilai Persentase Komponen Dimensi Literasi Informasi

\begin{tabular}{|c|c|c|c|c|}
\hline No. & Komponen & Nilai & Mean & Persentase \\
\hline 1. & Task Definition & 2842 & 355 & $86,65 \%$ \\
\hline 2. & Information Seeking Strategies & 1628 & 326 & $79,41 \%$ \\
\hline 3. & Location and Access & 975 & 325 & $79,27 \%$ \\
\hline 4. & Use of Information & 1370 & 274 & $66,83 \%$ \\
\hline 5. & Synthesis & 1164 & 291 & $70,98 \%$ \\
\hline 6. & Evaluation & 892 & 297 & $72,52 \%$ \\
\hline & Total & \multicolumn{2}{|c|}{8871} & $75,95 \%$ \\
\hline
\end{tabular}

Tabel 2 menunjukkan bahwa responden sudah dapat mengetahui masalah kecantikan yang sedang mereka alami, dan mereka telah dapat mengidentifikasi informasi kecantikan sesuai kebutuhan (86,65\%). Informasi tersebut seperti harga produk kecantikan, kandungan produk kecantikan, dan cara melakukan perawatan kecantikan.

- Pada komponen Information Seeking Strategies (79,41\%), responden aktif dalam menemukan sumber informasi kecantikan yang sesuai kebutuhan - mereka dapat menemukan sumber informasi kecantikan terbaik berdasarkan pemahaman mereka. Meskipun demikian, responden ada yang memilih beauty influencer sebagai sumber informasi kecantikan, misalnya sekitar $35,2 \%$ responden memilih konten yang bersifat ilmiah dari jurnal medis.

- Pada komponen Location and Access (79,41\%), responden dapat menentukan lokasi informasi kecantikan yang kredibel, yakni melalui Platform Female Daily Network.

- Pada komponen Synthesis (70,98\%), responden telah mampu mengatur, menyajikan, dan menampilkan informasi kecantikan yang telah mereka peroleh. Pengguna Female Daily Network dapat memilih informasi kecantikan secara cermat di internet, artinya mereka dapat membedakan informasi kecantikan yang tergolong hoax dan fakta. Selain itu, pengguna dapat berbagi informasi kecantikan dengan orang lain dan me-review produk pada Platform Female Daily Network.

- Pada komponen Evaluation (72,52\%), informasi kecantikan seperti tips kecantikan dan review produk yang diperoleh responden dari Female Daily Network cukup membantu dalam mengambil keputusan untuk membeli produk kecantikan.

- Pada komponen Use of Information (66,83\%), responden hanya mencari informasi terkait produk kecantikan dan menggunakan informasi review yang ada untuk bahan pertimbangan 
ketika membeli produk kecantikan. Mereka tidak terlalu aktif diskusi dalam forum kecantikan yang ada pada di Platform Female Daily Network.

Tabel 3. Indeks Literasi Informasi Kecantikan Pengguna Female Daily Network

\begin{tabular}{|c|c|c|c|}
\hline Persentase & \multicolumn{2}{|l|}{ Kategori Persentase } & Hasil Penelitian \\
\hline $16,7 \%-44,5 \%$ & Level 1 & Rendah & - \\
\hline $44,5 \%-72,3 \%$ & Level 2 & Sedang & - \\
\hline $72,3 \%-100 \%$ & Level 3 & Tinggi & $75,95 \%$ \\
\hline
\end{tabular}

Dapat dikatakan bahwa literasi informasi kecantikan di kalangan pengguna Female Daily Network termasuk kedalam kategori ketiga atau tinggi karena mimiliki nilai rata-rata sebesar 75,95\%. Hal ini menunjukkan bahwa platform ini banyak memberikan informasi seputar kecantikan yang dibutuhkan oleh responden. Female Daily Network juga menjadi salah satu sumber informasi kecantikan terbaik bagi responden.

\section{KESIMPULAN}

Pengguna Female Daily Network yang menjadi responden telah mampu mengatur, mencari dan mengelola informasi yang mereka dapatkan secara efektif dan efisien. Mereka telah menggunakan sebagian besar fitur yang ada pada Platform Female Daily Network untuk memenuhi kebutuhan informasi kecantikan. Mayoritas responden adalah remaja perempuan produktif yang berada pada rentang usia 21-25 tahun yang berasal dari golongan SES B. Hal ini menunjukkan bahwa mereka membutuhkan informasi seputar kecantikan untuk mendukung penampilan mereka dalam kehidupan sehari-hari. Responden merasa bahwa dengan mencari informasi kecantikan dapat mengatasi setiap permasalahan kecantikan yang mereka alami, seperti jerawat, kulit kusam, dsb. Dengan memilih sumber informasi yang kredibel seperti Female Daily Network, responden dapat terhindar dari bahaya hoax dan misinformasi kecantikan, serta kesalahan dalam penggunaan produk kecantikan. Peneliti menyarankan kepada pengguna agar Platform Female Daily Network dapat digunakan sebagai salah satu acuan pengadaan konten informasi kecantikan. Selain itu, perlu dilakukan penelitian lanjutan tentang literasi informasi pada UGC pada Platform Female Daily Network dari sudut pandang lain. 


\section{DAFTAR PUSTAKA}

Alodokter. $\quad$ n.d. Pemilihan Skin Care Untuk Wajah. https://www.alodokter.com/komunitas/topic/apa-yang-baik-untuk-kulit (accessed September $29,2019)$.

Amanda, C., Prijana, P., \& Yanto, A. 2017. Hubungan Perilaku Pencarian Informasi Perempuan dengan Kebutuhan Fashion. BACA: Jurnal Dokumentasi dan Informasi, 38(2). https://doi.org/10.14203/j.baca.v38i2.319.

Anunobi, C. \& Udem, O.K. 2014. Information Literacy Competencies: A Conceptual Analysis. Journal of Applied Information Science and Technology, 7(2), 64-80.

Bartow, C. \& Marion, J. n.d. TheBig6.Org. https://thebig6.org/ (accessed June 10, 2019).

Biradar, B. 2017. Information Literacy Model for Higher Education Institution in India. International Journal of Digital Library Services, 7, 31-50.

Bisnis Indonesia. n.d. Kemenperin: Produk Impor Kuasai Pasar Kosmetik. http://www.kemenperin.go.id/artikel/11943/Produk-Impor-Kuasai-Pasar-Kosmetik (accessed June 10, 2019).

Chetty, K., Qigui, L., Gcora, N., Josie, J., Wenwei, L., \& Fang, C. 2018. Bridging the Digital Divide: Measuring Digital Literacy. Economics: The Open-Access, Open-Assessment EJournal, 12, 1-20. https://doi.org/10.5018/economics-ejournal.ja.2018-23.

Hisle, D., \& Webb, K. 2017. Information Literacy Concepts, 1-61. http://hdl.handle.net/10342/6411\%0ADisplay/Hide MLA.

Ilahi, H.N. 2019. Women and Hoax News Processing on WhatsApp. Jurnal Ilmu Sosial dan Ilmu Politik, 22(2). https://doi.org/10.22146/jsp.31865.

Jeffrey, L., Hegarty, B., Kelly, O., Penman, M., Coburn, D., \& McDonald, J. 2017. Developing Digital Information Literacy in Higher Education: Obstacles and Supports. Journal of Information Technology Education: Research, 10, 383-413. https://doi.org/10.28945/1532.

Kay, R.H. \& Ahmadpour, K. 2015. Negotiating the Digital Maze of Information Literacy: A Review of Literature. Journal of Educational Informatics, 1, 1-25.

Laar, E.V., Deursen, A.J.A.M.V., Dijk, J.A.G.M.V., \& de Haan, J. 2017. The Relation Between 21st-Century Skills and Digital Skills: A Systematic Literature Review. Computers in Human Behavior, 72, 577-88. https://doi.org/10.1016/j.chb.2017.03.010.

Li, Y., Zhang, Z., Peng, Y., Yin, H., \& Xu, Q. 2018. Matching User Accounts Based on User Generated Content across Social Networks. Future Generation Computer Systems, 83, 10415. https://doi.org/10.1016/j.future.2018.01.041.

Lim, M. 2018. Dis/Connection: The Co-Evolution of Sociocultural and Material Infrastructures of the Internet in Indonesia. Indonesia, 105(1), 155-72. https://doi.org/10.1353/ind.2018.0006.

Lombard, E. 2016. Information Fluency: Not Information Literacy 2.0. Journal of Academic Librarianship, 42(3), 281-83. https://doi.org/10.1016/j.acalib.2016.04.006.

Luthfia, A. 2018. Risiko Online pada Remaja dan Pendidikan Literasi Media Baru. Jurnal Communicate, 2(1), 13.

Markplus.inc. 2018. Zap Beauty Index. Markplus.Inc. 
Newman, R., Chang, V., Walters, R.J., \& Wills, G.B. 2016. Web 2.0-The Past and the Future. International Journal of Information Management, 36(4): 591-98. https://doi.org/10.1016/j.ijinfomgt.2016.03.010.

Pieri, M. \& Diamantini, D. 2014. An E-Learning Web 2.0 Experience. Procedia - Social and Behavioral Sciences, 116, 1217-21. https://doi.org/10.1016/j.sbspro.2014.01.371.

Putri, R.D. 2017. Indonesia, Target Pasar Seksi K-Beauty di Asia. https://tirto.id/indonesia-targetpasar-seksi-k-beauty-di-asia-cyRj.

Sales, D. \& Pinto, M. 2016. Pathways into Information Literacy and Communities of Practice: Teaching Approaches and Case Studies. India: Chandos Publishing.

Silvana, T., Fitriawati, F., \& Saepudin, E. 2017. Study About Ability of Information Literacy Among Junior High School Students. Edulib, 7(7), 17-28.

Stock, W.G. \& Stock, M. 2013. Handbook of Information Science. Kerpen: Walter de Gruyter.

Sugiyono. 2013. Metode Penelitian Kuantitaf Kualitatif dan R\&D. Bandung: Alfabeta.

Sukritiani, D. 2014. Pengetahuan Tentang Kosmetika Perawatan Kulit Wajah dan Riasan pada Mahasiswi Jurusan Kesejahteraan Keluarga Fakultas Teknik Universitas Negeri Padang. Padang: Universitas Padang.

UNESCO. 2011. Digital Literacy in Education. Policy Brief.

Walter, S. 2007. Information Literacy Instruction: Theory and Practice (Review). Portal: Libraries and the Academy, 2(2), 344-45. 
